J. Lake Sci. (湖泊科学), 2015, 27(2): 195-199

http : //www. jlakes.org. E-mail : jlakes@niglas.ac.cn

(c) 2015 by Journal of Lake Sciences

\title{
滇池水环境综合治理成效与存在问题”
}

\author{
何 佳, 徐晓梅 ${ }^{* *}$, 杨 艳, 吴 雪, 王 丽, 李 森, 周鸿斌 \\ ( 昆明市环境科学研究院, 昆明 650032)
}

\begin{abstract}
摘 要: 湖泊治理是一个世界性难题, 也是当前我国亟待解决的重大问题, 滇池治理是当今我国湖泊治理的典型. 为总结 滇池治理成效并系统分析滇池水环境综合治理存在的问题, 对滇池 1987-2013 年的治理历程及治理措施进行了回顾. 结 果表明: 滇池治理的阶段性与水质变化具有一定的对应性, 1988-1995 年为治理的启动阶段, 1987-2000 年滇池水质迅 速恶化;1996-2005 年为全面治理阶段,2001-2009 年滇池水质缓慢改善;2006-2013 年为治理的提速阶段,2010-2013 年草海水质迅速改善, 外海水质波动性变化; 目前滇池水质恶化的趋势已基本得到遏制, 但仍存在流域社会经济过度发 展、水资源鿒乏、管理体制不完善等问题, 应加快实施污水处理设施和管网建设, 不断提高城市污水收集处理率; 强化流 域水体置换,实现滇池健康水循环; 进一步完善流域水环境管理体制与部门协作机制, 实施全域性的综合治理.
\end{abstract}

关键词: 滇池;治理历程;治理成效;存在问题

\section{Problems and effects of comprehensive management of water environment in Lake Dianchi}

\author{
HE Jia, XU Xiaomei, YANG Yan, WU Xue, WANG Li, LI Sen \& ZHOU Hongbin \\ (Kunming Institute of Environment Science, Kunming 650032, P. R. China)
}

\begin{abstract}
Lake management and pollution control is a worldwide problem and a major issue in China's environmental protection activities. The management of Lake Dianchi is a typical case in China. In order to summarize the effects of Lake Dianchi management and systematically analyze problems associated with Lake Dianchi management, we reviewed the control measures of Lake Dianchi from 1987 to 2013. The results showed that the phases of Lake Dianchi management was well correlated with the variation trend of water quality in Lake Dianchi. 1988 - 1995 was the starting phase of Lake Dianchi management and pollution control, while the water quality deteriorated quickly between 1987 and 2000. The comprehensive governance phase was from 1996 to 2005 , and the water quality improved slowly between 2001 and 2009. The speed-up governance phase of Lake Dianchi was from 2006 to 2013, when the water quality of Lake Caohai improved rapidly and that of Lake Waihai saw much fluctuation. So far, water quality deterioration trend has been controlled in the lake. However, Lake Dianchi is now facing problems including excessive development of social economy, water resources shortage, imperfect management system, etc. We should improve the sewage collection rate, strengthen the water replacement of Lake Dianchi, and realize the Lake Dianchi healthy water cycle, so as to improve the management system of Lake Dianchi.
\end{abstract}

Keywords: Lake Dianchi; management process; control effect; problems

滇池属长江流域金沙江水系, 位于昆明市西南, 属断陷构造湖泊, 是云贵高原最大的淡水湖泊. 滇池南北 长约 $40.4 \mathrm{~km}$, 东西平均宽约 $7 \mathrm{~km}$, 水面面积为 $309.5 \mathrm{~km}^{2}$. 滇池水域自 1996 年修建了船闸以后就被分割为 既相互联系,但又几乎互不交换的草海、外海两部分. 草海位于滇池北部, 平均水深 $2.5 \mathrm{~m}$, 面积 $11.14 \mathrm{~km}^{2}$, 约占全湖的 $3.6 \%$; 外海为滇池的主体, 平均水深 $5 \mathrm{~m}$, 面积 $298.36 \mathrm{~km}^{2}$, 约占全湖面积的 $96.4 \%$. 草海、外海 各有一人工控制出口, 向北经螳螂川、普渡河后, 汇人金沙江. 滇池人湖河流为 29 条, 属 12 个河系,除流经昆 明市区的 6 条纳污河, 其它都发源于流域北部、东部和南部的山地, 以及滇池上游的水库和龙潭等水源地,

* 国家水体污染控制与治理科技重大专项 (2012ZX07102) 资助. 2014-06-10 收稿;2014-11-22 收修改稿. 何佳 (1983 ), 女, 硕士研究生, 工程师; E-mail:hj19830204@ 163.com.

** 通信作者;E-mail:deszxb@163.com. 
其中 7 条河流流人草海、22 条河流流人外海,这些人湖河流流经人口密集的城镇、乡村以及磷矿区, 最后呈 向心状注人滇池 ${ }^{[1]}$. 由于滇池处于城市的下水口, 又属于自然演替过程中的衰老期, 从 1970s 后期开始受到 污染, 进人 1990s 污染速度明显加剧, 水体富营养化异常严重 ${ }^{[2-3]}$, 这成为影响和制约昆明区域经济社会发展 的重要因素. “九五” 开始,尤其是“十五” 以来,滇池污染治理的问题受到中央、省、市等各级政府的高度重 视,连续 4 个五年计划都纳人了国家“三河三湖”重点污染治理范围,其治理工作得到快速推进 ${ }^{[4]}$. 在政府主 导推进滇池治理的同时,社会力量也发挥着作用,共同推进滇池治理进程.

\section{1 滇池治理历程与成效分析}

\section{1 滇池治理历程}

滇池水污染始于 $1970 \mathrm{~s}$ 后期,随着社会经济的高速发展,水污染问题加剧,其污染治理经历了从单一的 工程措施向工程与生态相结合的综合措施转变,投资力度不断加大. “九五”、“十五” 期间, 滇池治理以工程 措施为主, “九五” 期间投资 31.03 亿元,工程内容主要为工业污染治理和城镇污水厂建设; “十五” 期间投资 增加到 77.99 亿元, 工程内容扩展到截污工程和生态修复,但并未从根本上解决滇池的水污染问题. 为此, “十一五” 期间, 提出了以“六大工程”为主线的综合治污思路,共投资 183.3 亿元,全面实施“环湖截污、农 业农村面源治理、生态修复与建设、人湖河道整治、生态清淤等内源污染治理、外流域引水及节水”六大工 程; “十二五”期间,滇池治理投资增加到 420.14 亿元,工程内容在“十一五”的基础上,进一步对 “六大工 程”进行提升和完善. “环湖截污工程”主要包括片区、集镇、村庄、河道、干渠(管)截污系统建设; “农业农村 面源治理工程”主要包括村庄“三池”建设、测土配方、秸秆粪便综合利用、IPM 技术等; “生态修复与建设工 程”主要包括湖滨湿地、林地、水源涵养林建设、“五采区”植被恢复、水土流失整治; “人湖河道整治工程”主 要指河道堵口查污、铺设截污管道、河道清淤、绿化; “生态清淤等内源污染治理工程”主要指底泥疏浚; “外 流域引水及节水工程”主要指饮用水源调配、滇池生态用水补给、再生水利用、雨水利用 ${ }^{[5-7]}$.

在实施一系列重大环保项目工程的同时,地方政府不断健全滇池治理的法规政策体系和监督管理体 系,加大滇池流域的综合整治力度. 2002 年和 2004 年,昆明市相继成立了 “滇池管理局” 和“滇池管理综合 行政执法局”;2008 年 1 月,昆明市成立了“滇池流域水环境综合治理指挥部”,统筹协调滇池治理过程中各 部门的相关工作; 为适应滇池流域的水环境保护,还相继成立了“滇池北岸水环境综合整治工程管理局”、 “环湖南岸工程指挥部”、“环湖东岸工程指挥部”、“彻底截污指挥部”、“水体置换指挥部”、“生态建设指挥 部”、“一湖两江”流域水环境治理专家督导组. 随之, 昆明市对滇池流域主要人湖河流正式施行“河(段) 长 负责制”, 将人湖河流的管理和治理工作落实到各级行政领导,实行分段监控、分段管理、分段考核、分段问 责,极大地调动了各方力量综合整治滇池人湖河流;2010 年 5 月施行了《昆明市河道管理条例》,2011 年 3 月修订并执行《昆明市城市排水管理条例》, 与此同时,省政府成立了滇池水污染防治专家督导组, 旨在加强 对滇池水污染防治工作的指导、检查和监督,推进各项重点工作和重点工程顺利实施;2013 年新制定并执行 《云南省滇池保护条例》; 这一系列重大措施的出台、实施和落实, 是滇池水环境改善的主要原因之一,在制 度上保障了滇池水污染综合整治效果的实现 ${ }^{[8]}$.

\section{2 滇池治理成效}

近年来,随着滇池流域社会经济的快速发展, 流域污染物产生量呈持续增加态势 ${ }^{[9]}$, 同时污染治理力度 也不断加大, 污染削减能力不断增强, 污染物人湖总量占污染物产生总量的比例持续下降. 由 1995 年的 95\% 以上下降至 2005 年的 50\% 左右,2013 年达到了 30\% 以下,治理成效显著,具体可划分为 3 个阶段.

1.2 .1 治理的启动阶段 (1988-1995 年) 滇池的水污染防治最早可追溯到 “七五” 期间, 1988 年昆明市颁 布实施了《滇池保护条例》,印发了《滇池综合整治大纲》,开始着手滇池的保护和治理工作. 1991 年第一污 水处理厂投产运行,处理规模为 $5.5 \times 10^{4} \mathrm{~m}^{3} / \mathrm{d}$, 对城市点源污染起到了一定的削减作用,至 1995 年, 污染物 人湖总量占污染物产生总量的 $95 \%$ 以上.

1.2 .2 全面治理阶段(1996-2005 年) “九五” 以来,滇池被列为国家重点治理的“三河三湖”之一,治理力 度不断加大. 1999 年开展了达标排放“零点行动”, 对流域重点工业企业进行拉网式检查, 工业污染得到有 效控制; 逐步实施农村面源污染治理、内源污染防治及生态建设与恢复工程;先后建成了第二、三、四、五、六 
污水处理厂、呈贡县和晋宁县污水处理厂、北岸截污葲站, 对人湖污染负荷有了进一步的削减, 至 2005 年, 污染物人湖总量占污染物产生总量的 $50 \%$ 左右.

1.2.3 治理的提速阶段(2006-2013 年) “十一五” 以来, 实施了滇池治理 “六大工程” (即: 环湖截污、农业 农村面源治理、生态修复与建设、人湖河道整治、生态清淤等内源污染治理、外流域引水及节水), 使流域污染 得到了有效控制. 2010 年新建了第七、八污水处理厂, 部分污水处理厂处理能力提升, 处理工艺进一步优化, 流 域污水处理规模达到 $113.5 \times 10^{4} \mathrm{~m}^{3} / \mathrm{d}$, 污水处理厂出水均达一级 $\mathrm{A}$ 标 (除总氮 $(\mathrm{TN}$ ) 外, 污水处理厂出水基本 达到地表水 IV 类标准), 人湖污染负荷大幅削减, 至 2013 年, 污染物人湖总量占污染产生总量的 $30 \%$ 以下.

1988-2013 年滇池治理阶段性成效如图 1 所示.

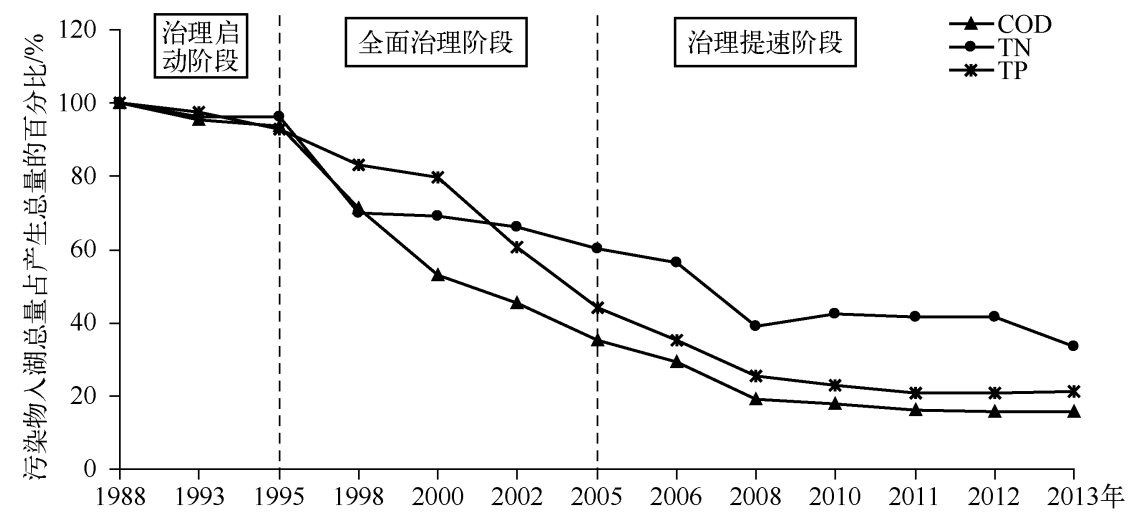

图 1 1988-2013 年滇池治理成效分析

Fig. 1 Effect analysis of Lake Dianchi management from 1988 to 2013

\section{3 滇池水质变化趋势分析}

由于湖泊治理的复杂性, 其水质变化对人湖污染负荷变化的响应相对滞后. 根据昆明市环境监测中心 历年来对滇池水质的监测结果, 与滇池治理的阶段性成效相对应, 滇池水质变化趋势也具有阶段性, 水质变 化可划分为迅速恶化阶段 (1987-2000 年)、缓慢改善阶段 (2001-2009 年)、草海的迅速改善阶段 (20102013 年) 与外海的波动阶段 (2010-2013 年).

1.3 .1 草海水质变化趋势分析 1987-2000 年, 草海水质迅速恶化, 总磷 $(\mathrm{TP})$ 和氨氮 $\left(\mathrm{NH}_{3}-\mathrm{N}\right)$ 呈现出显著 的增加趋势; 2001-2009 年, 草海水质呈现缓慢改善趋势, 化学需氧量 $\left(\mathrm{COD}_{\mathrm{Cr}}\right)$ 显著降低, 从 2000 年的 $146 \mathrm{mg} / \mathrm{L}$ 下降到 2009 年的 $41 \mathrm{mg} / \mathrm{L}$, 高锰酸盐指数 $\left(\mathrm{COD}_{\mathrm{Mn}}\right)$ 和五日生化需氧量 $\left(\mathrm{BOD}_{5}\right)$ 也分别在 2003 年和 2007 年出现历史最低值, 但 TN、TP、 $\mathrm{NH}_{3}-\mathrm{N}$ 仍呈波动上升趋势; 2010-2013 年, 草海水质显著改善, TP、 $\mathrm{NH}_{3}-\mathrm{N}$ 显著性降低,其余指标虽有波动, 总体也呈现下降趋势 (图 2a).

1.3.2 外海水质变化趋势分析 1987-2000 年,外海水质迅速恶化, $\mathrm{BOD}_{5}$ 、 $\mathrm{TN} 、 \mathrm{TP}$ 和 $\mathrm{NH}_{3}-\mathrm{N}$ 都呈增加趋势, 其中, $\mathrm{BOD}_{5}$ 和 TP 都在 1999 年出现历史最高值; $2001-2009$ 年, 外海水质缓慢改善, $\mathrm{BOD}_{5}$ 和 $\mathrm{TP}$ 显著降低, $\mathrm{BOD}_{5}$ 在 2007 年出现 $2.23 \mathrm{mg} / \mathrm{L}$ 的历史最低值, $\mathrm{COD}_{\mathrm{Cr}}$ 在 2009 年出现 $52.17 \mathrm{mg} / \mathrm{L}$ 的历史最低值, $\mathrm{COD}_{\mathrm{Mn}}$ 仍呈 上升趋势;2010-2013 年, 外海 $\mathrm{COD}_{\mathrm{Mn}}$ 和 $\mathrm{COD}_{\mathrm{Cr}}$ 呈显著上升趋势,其余指标呈波动变化 (图 2b).

总体上, 1980s-1990s 是滇池水质迅速恶化的时期, 这段时期流域经济迅速发展, 水环境保护效果还未 显现. 1999 年起, 昆明实施了 “零点行动”, 严格要求流域内工业企业达标排放, 同时, 结合 “十五” 和“十一五” 滇 池流域水污染防治规划成效, 滇池水质逐渐改善. 从 2009 年起, 滇池流域污水处理厂规模达到 $113.5 \times 10^{4} \mathrm{~m}^{3} / \mathrm{d}$, 大 大降低了点源人湖比例, 草海水质迅速改善. 然而, 外海由于周边集中了滇池流域主要城镇和农业, 面源污染不 可小觑, 水质改善对点源削减的响应较弱, 同时由于遭遇百年不遇特大干旱, 水质呈现波动变化, 部分污染 物浓度升高.

尽管从 2009 年起,外海水质未显示出和草海一样的迅速改善阶段,但是, 随着滇池 “十二五” 规划项目 的实施、外海周边面源污染治理的深人以及旱情的逐步缓解, 外海水污染治理的成效也将逐步显现出来. 

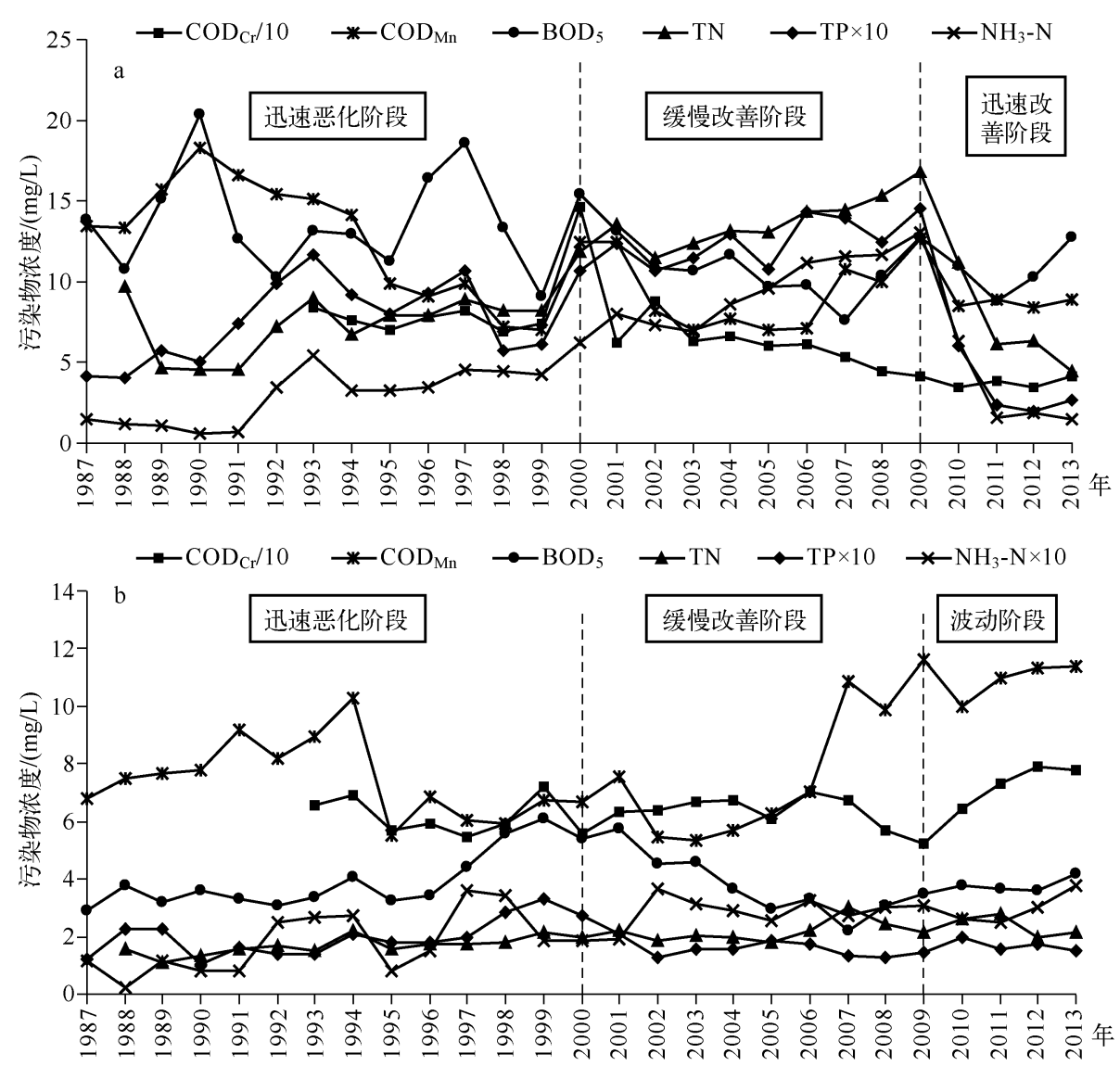

图 2 1987-2013 年草海 (a) 和外海 (b) 水质变化趋势

Fig. 2 Water quality trend of Lake Caohai(a) and Lake Waihai(b) from 1987 to 2013

\section{2 滇池水环境综合治理存在的问题}

自 “七五” 开展滇池治理以来, 滇池水环境治理经历了从单一的工程措施向工程与生态相结合的综合治 污措施的转变, 取得了阶段性成效, 水环境恶化的趋势基本得到遏制, 但水质至今未见根本好转, 滇池治理 仍面临诸多困难和问题.

\section{1 流域社会经济过度发展,超出环境容量}

滇池位于昆明市主城区下游, 流域内河流源近流短, 湖体成为城市污染物唯一最终受纳体. 随着城市污 水处理规模的不断增加, 污染负荷削减能力得到大幅提升, 污水处理规模从 2005 年的 $55.5 \times 10^{4} \mathrm{~m}^{3} / \mathrm{d}$ 增加 到 2010 年的 $110.5 \times 10^{4} \mathrm{~m}^{3} / \mathrm{d}$, 再增加到目前的 $135.5 \times 10^{4} \mathrm{~m}^{3} / \mathrm{d}$, 污染负荷人湖率已下降到 $30 \%$ 以下, 2013 年 $\mathrm{COD}_{\mathrm{Cr}} 、 \mathrm{NH}_{3}-\mathrm{N} 、 \mathrm{TN}$ 和 TP 人湖量分别为 $15782 、 4463 、 5435$ 和 $363 \mathrm{t}$. 但仍然有部分人湖污染物超过水环境 容量 (“十二五” 规划目标的 $\mathrm{COD}_{\mathrm{Gr}} 、 \mathrm{NH}_{3}-\mathrm{N} 、 \mathrm{TN}$ 和 TP 水环境容量为 $22957 、 8694 、 5072$ 和 $391 \mathrm{t}$ ) 的要求, 流域 社会经济发展环境压力巨大,仍需加大污水收集处理设施建设力度,进一步削减人湖污染负荷.

\section{2 流域水资源匮乏,生态用水难以保证}

滇池是典型的宽浅型高原湖泊, 人湖水量主要来源于流域自然降水, 多年平均人湖径流量为 $9.7 \times 10^{8} \mathrm{~m}^{3}$, 扣除湖面蒸发量 $4.3 \times 10^{8} \mathrm{~m}^{3}$, 多年平均水资源量为 $5.4 \times 10^{8} \mathrm{~m}^{3}$, 多年平均出湖水量为 $4.0 \times 10^{8} \mathrm{~m}^{3}$, 换水周 期约 4 年一次, 用水量远超过水资源量, 水资源开发利用率达到 $161 \%$,资源性和水质型缺水并存. 由于 2009-2013 年滇池流域连续 5 年干旱, 流域降雨量及人湖水量均减少, 以致 2010-2013 年滇池平均出湖水 
量比多年平均出湖水量减少了 $1.98 \times 10^{8} \mathrm{~m}^{3}$, 减少了 $46.9 \%$. 其中滇池外海平均出湖水量只有 $0.72 \times 10^{8}$ $\mathrm{m}^{3}$, 外海换水周期已延长到 20 年以上, 导致污染物在滇池湖体内浓缩富集, 污染程度加深 ${ }^{[10-11]}$.

\section{3 管理体制不完善,科学管理水平有待提高}

在滇池治理过程中, 昆明市政府为推进滇池治理出台了《昆明市 “一湖两江” 流域水环境治理 “四全”工 作行动计划》、《昆明市治污减排问责工作规定》、《关于进一步加强集中式饮用水源保护的实施意见》等若 干规定; 同时借滇池治理之机推进经济结构调整, 出台了如《关于鼓励支持主城区企业节能减排降低成本搬 迁人园异地发展的实施意见》、《昆明市人民政府关于批转滇池流域污水全面截流收集处理设施建设工作方 案的通知》等, 虽然政策制定者的初衷是好的, 但这些政策间的协调性不够, 加强治污问责与官员政绩考核 不协调; 加快促进企业搬迁人园区并不意味着企业节能减排降低成本, 更不意味着滇池污染源的减少. 同 时, 部分已建环保设施因配套工程不完善等原因, 运行管理不到位, 未充分发挥项目的环境效益. 另外, 社会 组织与公民对滇池治理的热情不高, 虽然昆明市政府在 2011 年的《政府工作报告中》提出了“市民河长制”, 希望将民众的力量与政府的期望相融合, 然而由于参与机制及参与条件的缺失,市民的热情并不高.

\section{3 结论与建议}

滇池治理是一个复杂的系统工程, 从 $1980 \mathrm{~s}$ 初至今, 昆明市政府无论是从财力还是人力、物力上一直在 不遗余力地加大投人. 在治理资金的来源方面, 从以政府财政投人为主体向以政府财政投人为杜杆调动广泛 社会资金投人转变; 在治理方式上, 由之前的重技术投人、重末端治理向技术与机制建设并重、末端治理与源 头治理共举转变; 在治理思路上, 从之前的单方面的重机制建设向更加重视制度建设转变. 通过近 30 年的不断 努力,滇池治理取得了初步成效,但仍然任重道远,需要从以下几方面来持续推进滇池治理工作:

1) 加快实施污水处理设施和管网建设,不断提高城市污水收集处理率,污水处理规模由 “十一五” 的日 处理 $110.5 \times 10^{4} \mathrm{~m}^{3}$ 增加到 $202.0 \times 10^{4} \mathrm{~m}^{3}$, 更好地发挥截污工程的整体功能作用.

2）强化流域水体置换, 抓好 “外流域引水及节水工程”. 利用牛栏江通水后的补水, 进一步优化滇池流 域水资源调配, 增强昆明主城供水保障, 加快污水处理厂尾水外排和资源化利用工程, 实现滇池健康水循 环.继续推进城市节水工作,鼓励再生水利用扩大供应范围和提高处理标准.

3 ) 进一步完善流域水环境管理体制与部门协作机制, 形成以地方政府为主导、广泛吸纳相关企业以及 公民社会组织积极参与并承担相应责任的网络化治理制度; 强化运行管理, 建立长效运管机制, 明确已建设 施的运营责任主体, 落实项目运行资金, 尽量发挥已建设施作用; 明确公众参与水环境决策的法律程序, 提 高公众参与的透明度; 完善水环境状况通报制度, 让公众了解本地区的水环境状况, 为公众提供科学、准确 的环境污染状况数据.

致谢: 感谢昆明市环境监测中心在水质监测数据方面给予的支持和帮助.

\section{4 参考文献}

[ 1 ] 昆明市水利局水利志编写小组. 滇池水利志. 昆明:云南人民出版社,1996.

[2 ] Xing KX, Guo HC, Sun YF et al. Assessment of the spatial-temporal eutrophic character in the Lake Dianchi. Acta Geographica Sinica, 2005, 15(1) : 37-43.

[ 3 ] Gong ZJ, LI YL, Shen J et al. Diatom community succession in the recent history of a eutrophic Yunnan Plateau lake, Lake Dianchi, in subtropical China. Limnology, 2009, 10(3) : 247-253 .

[ 4 ] 潘 珉,高 路. 滇池流域社会经济发展对滇池水质变化的影响. 中国工程科学,2010,12(6): 117-122.

[5] 刘 永, 阳平坚,盛 虎等. 滇池流域水污染防治规划与富营养化控制战略研究. 环境科学学报, 2012,32 (8): 1962-1972.

[6] 杨健强. 滇池污染的治理和生态保护. 水利学报, 2001, (5) : 17-21.

[ 7 ] Lu SY, Zhang PY, Xiang CS. Phosphorus removal by constructed wetland treating agricultural runoff in Dianchi region of China. Chinese Journal of Geochemistry, 2006, 25(1):258.

[ 8 ] 刘瑞志, 朱丽娜, 雷 坤等. 滇池人湖河流“十一五”综合整治效果分析. 环境污染与防治, 2012,(3):95-100.

[ 9 ] 李中杰,郑一新,张大为等. 滇池流域近 20 年社会经济发展对水环境的影响. 湖泊科学,2012,24(6):875-882.

[10］方 淋. 昆明滇池的污染成因与治理分析. 中国科技产业,2007,10:79-82.

[11] 张召文. 云南九大高原湖泊治理的复杂性、艰巨性和长期性. 云南环境科学, 2012, (1) : 19-20. 